\title{
Um Caminho com Sartre: Apropriações de seus Métodos para uma Clínica
}

\author{
Fenomenológica-Existencial
}

\author{
Rodolfo Rodrigues de Souza* \\ Universidade do Estado do Rio de Janeiro - UERJ, Rio de Janeiro, RJ, Brasil \\ ORCID: http://orcid.org/0000-0002-6204-1073
}

\begin{abstract}
RESUMO
O pensamento do filósofo francês Jean-Paul Sartre é atravessado pela constituição de diferentes propostas metodológicas. No fim da década de 1930, fala em um método regressivo ao estudar as relações entre imaginação e consciência. Em $O$ Ser e o Nada, de 1943, apresenta a Psicanálise Existencial, ora tomada como um método em si, ora como uma proposta que se vale de um método, chamado de comparativo. Já em 1957, com Questões do Método, apresenta o método progressivo-regressivo, em maior contato com o pensamento marxista e com a História. Este artigo busca apresentar tal caminhada metodológica, ensaiando diálogos com o campo da psicoterapia fenomenológica-existencial. Defende-se que todas essas diferentes propostas formam uma totalidade de olhares que torna mais complexa as possibilidades de compreensão do analisando no horizonte clínico. O estudo do método progressivo-regressivo, em adição à Psicanálise Existencial, cujas relações com o campo da clínica parecem mais evidentes, permite a constituição de um fazer que não recaia em uma prática interpretativa ou explicativa.
\end{abstract}

Palavras-chave: fenomenologia-existencial, psicanálise existencial, método progressivoregressivo, Jean-Paul Sartre.

\section{A Path with Sartre: Appropriations of his Methods for a}

\section{Phenomenological-Existential Clinic}

\begin{abstract}
The thinking of the French philosopher Jean-Paul Sartre is crossed by the constitution of different methodological proposals. In the late 1930s, he wrote about a regressive method when studying the relationship between imagination and consciousness. In Being and Nothingness, from 1943, he presents the Existential Psychoanalysis, sometimes taken in the text as a method in itself and other times as a proposal that uses a method, called comparative. In 1957, with Search for a Method, he presented the progressive-regressive method, in greater contact with Marxism and History. This article seeks to present such a methodological path, attempting dialogues with the field of phenomenological-existential psychotherapy. It is
\end{abstract}


argued that all these different proposals form a totality of views that gives a new complexity to the possibilities of understanding the client in the clinical horizon. The study of the progressive-regressive method, in addition to Existential Psychoanalysis, whose relations with the clinical field seem more evident, allows the constitution of a practice that does not fall into an interpretative or explanatory practice.

Keywords: existential phenomenology, existential psychoanalysis, progressive-regressive method, Jean-Paul Sartre.

\title{
Un Camino con Sartre: Apropiaciones de sus Métodos para una Clínica
}

\author{
Fenomenológica-Existencial
}

\section{RESUMEN}

El pensamiento del filósofo francés Jean-Paul Sartre está atravesado por la constitución de diferentes propuestas metodológicas. A fines de la década de 1930, escribió acerca de un método regresivo al estudiar la relación entre la imaginación y la conciencia. En El Ser y la Nada, de 1943, presenta el psicoanálisis existencial, a veces tomado como un método en sí mismo y en otras como una propuesta que utiliza un método, llamado comparativo. En 1957, con Cuestiones de método, presentó el método progresivo-regresivo, en mayor contacto con el pensamiento marxista y con la historia. Este artículo busca presentar un paseo por estas cuestiones metodológicas, ensayando diálogos con el campo de la psicoterapia fenomenológico-existencial. Se argumenta que todas estas propuestas diferentes forman una totalidad de puntos de vista que confieren complejidad a las posibilidades de comprender el cliente en el horizonte clínico. El estudio del método progresivo-regresivo, además del psicoanálisis existencial, cuyas relaciones con el campo clínico parecen más evidentes, permite la constitución de una práctica que no cae en un hacer interpretativo o explicativo.

Palabras clave: fenomenología existencial, psicoanálisis existencial, método progresivoregresivo, Jean-Paul Sartre.

Jean-Bertrand Pontalis teve uma longa relação com Jean-Paul Sartre. Além de exaluno, Pontalis se tornou integrante, a partir de 1964, da equipe editorial da revista dirigida pelo filósofo, Les Temps Modernes, muito embora seus textos já fossem ali publicados desde a década de 1950. Na coletânea En marge des nuits (Pontalis, 2010), o psicanalista registra algo que parece valer como testemunho da relação de Sartre com seus alunos e seguidores: "Sartre, que se recusava obstinadamente a ser um mestre, não queria discípulos. A cada um caberia inventar seu caminho de liberdade. Isso não impede a alguns de tentarem caminhar sobre suas pegadas" ${ }^{1}$ (Pontalis, 2010, p. 18). 
No mesmo sentido corroboram inúmeras cenas narradas por Annie Cohen-Solal (2008). Em sua biografia sobre Sartre, registra que ele alimentava certo temor em lecionar, um dos motivos sendo o provável aprisionamento que o funcionalismo público poderia acarretar. Este temor deve ter contribuído para que o jovem professor que começou a trabalhar no liceu François I, na cidade costeira de Havre em março de 1931, aos 25 anos, fosse pouco usual. Sartre se portava de modo diferente daquele de seus colegas docentes-funcionáriospúblicos, por exemplo, saindo com seus alunos para conversas regadas a álcool, cigarros e discussões sobre filosofia e trivialidades.

Ainda, segundo a literata Aliocha Wald Lasowski,

(...) as ideias de Sartre (1905-1980) não se limitam às proposições teóricas definitivas ou à posições fixas de engajamento político e ideológico: ao contrário, elas se inscrevem em uma revolução permanente de poderes da linguagem, em uma renovação constante das formas de comunicação com o outro, em um questionamento contínuo da estranheza do mundo por meio de novas práticas de escrita e pensamento. (Lasowski, 2011, pp. 11)

Diante dessas narrativas, afirmo que o que busco neste artigo não é seguir os passos de Sartre, mas me apropriar da caminhada que ele realizou. O que empreendo aqui é uma busca por pensar sobre conexões entre o caminho reflexivo de Sartre até a constituição de seu método progressivo-regressivo (Sartre, 2002) e a prática clínica fenomenológica-existencial. Tomo a expressão caminho reflexivo como sinônima de método, uma vez que este termo é oriundo da contração de metá (reflexão) e hódos (caminho). Farei um esforço por não caminhar sobre as pegadas de Sartre, mas buscar, nos limites deste trabalho, refazer o caminho deste último filósofo (Renaut, 1993), em um esforço de reconhecer suas pegadas e como elas podem inspirar o meu fazer. Na medida do possível, será um caminhar-com Sartre.

Tal empreitada será baseada não na análise de um caso clínico específico, mas a partir da própria revisão deste método ao longo da elaboração do pensador. Assim, parto de um olhar para como o(s) método(s) é(são) desdobrado(s) ao longo da produção de Sartre, sempre buscando conectá-lo(s) com o horizonte histórico em que tal ou qual metodologia foi engendrada por ele. A título de conclusão, estabeleço reflexões sobre o campo da clínica. Reforço de partida a defesa de que toda a apresentação das discussões metodológicas em Sartre, ao buscarem compreender uma singularidade diante do universal, apontam para o fazer da clínica psicológica. 


\section{O Início das Reflexões de Sartre}

Diversos foram os autores que se debruçaram sobre a história de Sartre. Em uma abordagem biográfica e panorâmica, embora não enciclopédica, a obra Sartre: uma biografia, de Cohen-Solal (2008) é uma excelente fonte. Outra abordagem, mais centrada no caminho intelectual do pensador em relação com sua biografia, Sartre, le dernière philosophe de Alain Renaut (1993), e a tese de doutoramento de Luciano Donizetti da Silva (2010), A filosofia de Sartre: entre a Liberdade e a História, são exemplares. Uma visada introdutória tanto às ideias quanto à biografia de Sartre pode ser encontrada em Jean-Paul Sartre, une introduction, da literata francesa Lasowski (2011), e em Sartre: existencialismo e liberdade, de Luiz Damon S. Moutinho (1995).

Sartre nasceu em 21 de junho de 1905, ano em que ocorre a primeira revolução bolchevique na Rússia. O momento em que nasce e as condições em que veio ao mundo fazem parte da trajetória do menino e do homem Sartre. Por nascimento, é burguês. Mas o que encontrará é um mundo repleto de clamores pelo combate aos valores e costumes dessa mesma classe que o criara. Os reclames trabalhistas, a marcha do comunismo, a crescente laicização dos Estados (é em 1905, por exemplo, que a lei que separa Estado e Igreja é promulgada na França) são alguns dos movimentos crescentes à época. Ainda criança, Sartre veria também o início da Primeira Guerra para, não muito tempo depois, ser cooptado para a Segunda, bastante devastadora principalmente para os países europeus. Seu fazer será marcado por tal tempo, ao mesmo instante em que Sartre se inscreveria no mundo.

De partida, a via que escolhe para tal inscrição é o pensamento. Assim, aos 18 anos, opta pelo curso de filosofia da Escola Normal Superior de Paris. Entretanto, o pensamento para ele tem status diferente do que para outros intelectuais. Contra uma philosophie dans le boudoir ${ }^{2}$, Sartre pretende criar uma obra encarnada, desdobrada em atos concretos no mundo. O modo de ação que privilegiará até meados da década de 1940 será a escrita. É justamente essa relação intensa com a leitura e a produção escrita o fio condutor do texto autobiográfico As palavras (Sartre, 2011), lançado em 1964. Além de ensaios filosóficos, Sartre também escreve inúmeros roteiros para o cinema, críticas de cultura, romances e peças de teatro.

Quanto ao que alimentaria o cerne de seu pensar, ao modo de um diálogo que o acompanhará por toda a vida, cabe citar a Fenomenologia husserliana, a ontologia de Heidegger, a filosofia do instante de Bergson, dentre outros. Ao lado da fenomenologia, o pensamento marxista, como veremos mais adiante, tem grande importância em suas reflexões. A obra de Sartre passeia por reflexões nas áreas da filosofia, sociologia, antropologia, 
história, e da psicologia. Sobre essa, Daniele Ribeiro Schneider (2002), aliás, defende que Sartre tinha por "projeto fundamental" sua reformulação. Tal feito se dá de modo gradual ao longo das elaborações metodológicas de Sartre, culminando no método progressivoregressivo.

\section{O Método Regressivo nas Primeiras Obras}

O caminho de reflexão de Sartre requer compreender a sua busca por uma filosofia centrada no concreto. A própria anedota que narra o modo pelo qual ele se interessou pelo estudo da fenomenologia husserliana, no famoso episódio do coquetel de damasco de 1933 (Cohen-Solal, 2008, p. 128), aponta para esse desejo. Entretanto, segundo Sartre, tal interesse é ainda anterior a este ano. Em Questão do Método, lançado em 1957 como artigos na revista Les Temps Modernes, escreve que, em 1925, quando tinha vinte anos, já "exigíamos [ele e os demais de sua geração] uma filosofia que levasse em consideração tudo" (Sartre, 2002, p. 29). Segue o filósofo, "Entre nós, nessa época, o livro de Jean Wahl, Vers le concret [lançado em 1932], obteve muito sucesso. Ainda assim, ficamos decepcionados com esse 'vers' (...)" (Sartre, 2002, p. 29). Sendo vers uma partícula que indica movimento em direção a, ao falar de sua decepção, Sartre evidencia que já gostaria de estar diante do concreto.

De acordo com Lasowski (2011), Wahl foi um pensador dedicado principalmente ao diálogo com as obras de Hegel, Nietzsche e Kierkegaard e preocupado com as questões da existência singular. Ora, este é o tema central dos primeiros escritos de Sartre, culminando com O Ser e o Nada (Sartre, 2007), lançado em 1943. Portanto vemos já no interesse por Wahl o cerne da questão que o mobilizará por toda a vida: a compreensão do ser humano concreto e seu fazer-se no mundo.

Ainda sobre este trecho em que fala de Vers le concret, é curioso notar o inegável equívoco cronológico de Sartre. Afinal, situa a narrativa no ano de 1925, mas a obra de Wahl só foi lançada em 1932. Diante desse equívoco, penso nas razões que fizeram com que Sartre reunisse, à época em que escrevera Questão do Método, todo o período que vai de 1920 aos primeiros anos de 1930 em um único bloco datado como 1925. O equívoco, a meu ver, indica que a preocupação do filósofo durante todo esse período foi a mesma: o interesse pelo concreto será um dos nortes de seu projeto como pensador. Nesse sentido, é importante pensarmos que trazer as propostas de Sartre para a clínica requer considerar a concretude da existência que cada analisando apresenta para nós a cada nova consulta. 
Movido por essa busca pelo concreto, Sartre se debruça sobre a Fenomenologia, de onde se apropriará, de maneira cada vez mais singular ao longo de sua obra, da ideia de consciência intencional (Da Silva, 2010). Esta noção, que aponta para a máxima "toda consciência é consciência de alguma coisa", é mais bem desenvolvida por Sartre no livro $A$ transcendência do Ego (Sartre, 1991), que veio à público em 1936. Tal ideia, associada a alguns preceitos da metodologia fenomenológica como defendida por Husserl, estará presente em toda sua obra, direta ou indiretamente, sendo o ponto de partida para a "ontologia fenomenológica" proposta em O Ser e o Nada (Sartre, 2007).

É também de 1936 o lançamento da obra A Imaginação (Sartre, 2008). Segundo Moutinho e Bento Prado Júnior (1996, p. 5, grifos no original), "seu interesse [de Sartre] pelo

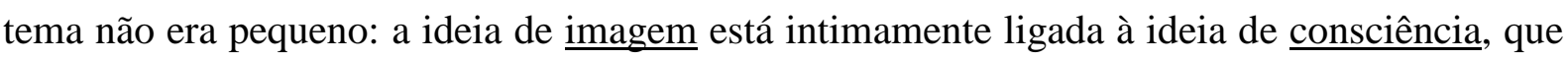
obsedava o jovem filósofo". Primeira parte de um díptico, A Imaginação é, ainda segundo Moutinho e Prado Jr. (1996), a parte crítica desta empreitada. Neste livro, em que se pode notar o interesse de Sartre pela psicologia, ele revisa criticamente ideias acerca da imaginação e da imagem presentes na filosofia moderna. Busca desconstruir o que chamou de "metafísica ingênua da imagem", um modo de pensar que a considera como reprodução fiel daquilo que representa (Sartre, 2008). A obra se encerra com uma promessa de retomar o tema, enfrentando-o sob um ponto de vista da Fenomenologia de Husserl.

É, portanto, em O Imaginário (Sartre, 1996), lançado em 1940, segunda parte do referido díptico, que Sartre empreende um projeto original - "ousado", para concordar com os referidos Moutinho e Prado Jr (1996). Com base na noção de intencionalidade, a proposta aqui é "expulsar" qualquer conteúdo que até então era pensado como imanente da consciência. Totalmente translúcida, ela intenciona, volta-se para, mira o mundo, sendo vazia de conteúdos. Nesse sentido, ela não contém representações imagéticas do mundo, como acreditavam as abordagens da "metafísica ingênua da imagem" (Sartre, 2008), mas relacionase com este de modo inequívoco.

Aproximando-se da ideia de ser-no-mundo de Heidegger entre os anos de 1936 e 1940, é pelo modo como lida com esta noção, segundo Da Silva (2010), que Sartre consegue suprimir parte dos conflitos da filosofia até o momento. Partindo da consciência como intencionalidade, e da articulação de tal definição com a ideia de uma intrínseca relação do ser da consciência com as aparições do mundo, Sartre visa ultrapassar a dualidade entre consciência e mundo. Consegue postular, se não a existência de um concreto, ao menos a necessidade absoluta de que, para existirem, consciência e mundo somente podem estar em relação. Assim, não há mundo sem consciência, nem consciência sem mundo. Neste sentido, é 
importante recuperarmos a ideia de que cada analisando realiza-se em um mundo situado; as escolhas que lhe aparecem como possíveis em dado momento são escolhas que se engendram nessa conexão indissociável entre ele e seus arredores. A partir de Sartre, não é possível fazer uma clínica de uma subjetividade interiorizada, cujos movimentos se dão a partir de qualquer dinâmica intrapsíquica, mas apenas na consideração das conexões entre cliente e mundo.

Nas elaborações de $O$ Imaginário (Sartre, 1996), a possibilidade de uma tal consideração já se coloca em termos regressivos, embora ainda não justaposto ao método progressivo. Diz Sartre, quase ao final da obra, que a análise da relação entre consciência e imaginação deverá ser desenvolvida "pelos procedimentos comuns da análise crítica, quer dizer, por um método regressivo" (Sartre, 1996, p. 234).

[...] apresentará dados concretos e, da análise desses dados, determinará quais são seus princípios, ou seja, o que se busca numa análise são justamente os princípios fundamentais. Por isso se trata de um método regressivo: regride do dado ao princípio, vai do complexo ao simples, do composto ao unitário. (Da Silva, 2010, pp. 263, grifos no original)

Ou seja, é pela adoção do método que chama de regressivo, num movimento do dado mais evidente e geral, rumo ao mais específico e singular, que Sartre consegue chegar ao homem no mundo apresentando-se concretamente à consciência. Há aqui um movimento de evidenciar a singularidade.

Poderíamos pensar que o próximo passo seria acrescentar a este método o aspecto progressivo para que tenhamos, assim, o método progressivo-regressivo. Contudo, não é esse o caminho de Sartre: antes de chegar à Questão de Método, defenderá em O Ser e o Nada certa análise do homem concreto a que irá nomear de psicanálise existencial. É sobre essa analítica, que ora define como método em si e ora diz valer-se de um método comparativo, que me deterei agora.

\section{A Psicanálise Existencial: um Método?}

Três anos depois de O Imaginário, Sartre lança em 1943 a obra máxima daquela que, para alguns, é a sua primeira fase: O Ser e o Nada: Ensaio de Ontologia Fenomenológica (Sartre, 2007). Não me aterei aqui às noções desenvolvidas nesta ontologia - tais como em-si, para-si, má-fé e para-outrem. Sobre tais definições, remeto o leitor à obra panorâmica de 
Bornheim (2007). Partirei diretamente para a última parte deste livro. É lá que se encontram delineamentos para uma Psicanálise Existencial.

Fundamental para esta psicanálise é a ideia de projeto. Ao definir a consciência como intencional, Sartre a coloca como puro movimento ao exterior. Sendo a consciência o modo de ser do humano, este se desdobra em um existir que é um lançamento constante em direção ao futuro: projeto. A psicanálise existencial é o método para a investigação desse projeto, desse modo como cada indivíduo "se anuncia e se define pelos fins que persegue" (Sartre, 2007, p. 682). Esse projeto se constitui pelas escolhas que cada pessoa faz na busca incessante por ser um em-si-para-si, pois, como escreve Sartre, "o homem é fundamentalmente desejo de ser" (Sartre, 2007, p. 692. grifos no original). Cabe, portanto, a um método que tenha por finalidade o estudo do humano, conseguir se debruçar sobre cada ato de um ser no mundo, cada momento sendo indicativo de uma escolha por um modo específico de ser. A unificação desses diversos atos seria a compreensão final daquilo que é o projeto fundamental daquele existente concreto. Genericamente, Sartre (2007) defende que o que move o humano é a busca por ser em-si-para-si, que simplificadamente podemos traduzir como uma busca por certa objetivação de si no mundo mantendo seu caráter de indeterminação e abertura, um projeto evidentemente paradoxal. Essa definição genérica, contudo, não perde de vista que o modo como cada um se estabelece nessa busca é singular.

A psicanálise existencial será, portanto, um método que acompanha o modo como as escolhas, as pequenas objetivações de si no mundo, se desdobram, em busca da compreensão de um sentido, de um norte, de um projeto singular. O termo compreensão, em si, já aponta para uma diferença em relação à tradição psicológica que Sartre critica por meio de sua proposta. Tendo sido emprestado dos trabalhos do pensador e psiquiatra alemão Karl Jaspers, o termo aponta para uma busca pelos sentidos mais do que pelas causas. Cabe um olhar compreensivo acerca do "para quê", ao invés de uma busca desenfreada pelo "por que" - este recai, na maior parte das vezes, sobre o que Sartre (2007, p. 685) chama de "grandes ídolos explicativos de nossa época - hereditariedade, educação, meio, constituição fisiológica".

Entretanto, escreve o filósofo, a compreensão como pensada pela psiquiatria continua sendo genérica. Ela se volta para cada comportamento de uma pessoa e os compreende separadamente e não em um movimento mais amplo que busque perceber como a pessoa se constitui ao longo de sua existência (Sartre, 2007). A meu ver, este movimento compreensivo criticado por Sartre é aquele presente em sua proposta de um método unicamente regressivo. Assim, ao ampliar a noção de compreensão, não mais como um movimento analítico- 
regressivo, mas pensando-a como uma busca por alguma unidade, Sartre aponta também para a necessidade de realização de um movimento sintético.

Esta "unidade - da qual a substância não passa de uma caricatura -, unidade que há de ser unidade de responsabilidade, unidade amável ou odiosa, repreensível ou louvável, [é] em suma: pessoal" (Sartre, 2007, p. 687). A pessoa é, em Sartre, justamente esse caminhar para uma síntese de si no mundo, o modo como cada humano se desdobra na escolha de seus possíveis. Portanto, pessoa não é self, id, ego, superego ou qualquer outro termo definidor, essencial e substancializado, mas abertura no e para o mundo. "Assim, o projeto fundamental, ou pessoa, ou livre realização da verdade humana encontra-se por toda parte, em todos os desejos (...)" (Sartre, 2007, p. 694).

Olhar para cada momento de "livre realização" compreensivamente ainda não é um interrogar-se sobre a unidade, que exige um movimento sintético. Sartre indica que a experiência vivida é o ponto de partida do método batizado de psicanálise existencial, mas é na possibilidade de uma compreensão unificada de todas essas experiências que reside sua proposta. Para tanto, escreve:

Seu método [aquele da psicanálise existencial] é comparativo: uma vez que, com efeito, cada conduta humana simboliza à sua maneira a escolha fundamental a ser elucidada, e uma vez que, ao mesmo tempo, cada uma delas disfarça essa escolha sob seus caracteres ocasionais e sua oportunidade histórica, é pela comparação entre tais condutas que faremos brotar a revelação única que todas elas exprimem de maneira diferente. (Sartre, 2007, pp. 696, grifos no original)

O trecho acima abre o caminho para fecharmos a discussão sobre a Psicanálise Existencial no que tange à discussão metodológica. Neste trecho, Sartre indica que o método desta psicanálise é comparativo. Mas não seria a própria Psicanálise Existencial um método? Retomando a ideia já apresenta acerca da tese de Schneider (2002) de que Sartre tem por projeto fundamental a reformulação da psicologia, a autora diz que, nessa etapa de $O$ Ser e $O$ Nada, “(...) Sartre entende que é necessário criar um método para a psicologia que denominará de 'psicanálise existencial'”. (Schneider, 2002, p. 113, grifos no original). Portanto, Schneider (2002) compreende a psicanálise existencial como um método necessário à realização do projeto de Sartre. Essa ideia é corroborada também por outros autores. Cannon (1991, p. 168) diz que Sartre "define a psicanálise existencial como 'um método inicialmente preocupado em estabelecer o modo pelo qual uma criança vive suas relações familiares numa 
dada sociedade", 3 . Ideia similar pode ser encontrada no artigo de Campos e Alt (2009, p. 191), que apresentam a psicanálise existencial como "método desejado pelo filósofo [que] se propõe a cumprir a tarefa de oferecer alternativas ao estudo do homem que escapem ao referencial da concepção analítica da psicologia”.

A meu ver, a confusão estabelecida se deve a certo descuido de Sartre na escolha terminológica. Neste sentido, reitero que a psicanálise existencial se sustenta como a parte analítico-regressiva que, como vimos, Sartre havia apresentado em $O$ Imaginário (Sartre, 1996), acrescida de um movimento sintético. Afinal, não basta o olhar regressivo para diferentes "princípios" das experiências vividas pelos analisandos, é preciso reintegrá-los no todo que perfaz o sentido existencial daquela pessoa. O problema aqui é que a síntese ainda parece terminar na pessoa, em sua história singular, não havendo a explicitação de uma necessária conexão da síntese com o mundo e história. Este será o importante acréscimo das elaborações de Questão do Método (Sartre, 2002).

\section{De O Ser e o Nada à Crítica da Razão Dialética}

O lançamento de O Ser e o Nada, que ocorre em 1943, está bastante próximo de uma mudança de Sartre com relação ao modo como desdobraria seu próprio projeto existencial. Em As palavras (Sartre, 2011), de 1964, o filósofo compreende sua relação fundamental com a escrita e com a leitura e como estas o mobilizam até meados da década de 1940. Neste sentido, lê-se em Moutinho (1995, p. 20) que "desde a notoriedade alcançada em 1945, Sartre intensificou sua ação política. A tal ponto que passou a dedicar-se menos à literatura (...)”. Sobre a escrita, Sartre registra:

É meu hábito e também meu trabalho. Por muito tempo tomei minha pluma como uma espada, atualmente reconheço nossa impotência. Não importa: eu faço, eu farei livros; devo fazê-lo [...] nós nos desfazemos de uma neurose, mas não nos curamos de nós mesmos. (Sartre, 2011, pp. 205)

Esse período mais voltado à ação política - sem se privar da escrita, embora ela adquira caráter secundário - é também aquele em que Sartre se relaciona mais intensamente com o marxismo. Já em $O$ Ser e o Nada, vemos comentários do filósofo em relação ao pensamento marxista. É assim que, por exemplo, critica em sua ontologia certa tendência de tal vertente a explicar os fatos com base em um conceito geral e a-histórico (Sartre, 2007, p. 
630). Tal "guinada" para a ação política direta é entendida por alguns autores como uma segunda fase de Sartre.

É assim, por exemplo, para Munné (1982): o primeiro Sartre, mais devotado às reflexões psicológicas, é aquele de $O$ Ser e o Nada; já o segundo, volta-se para o social, sendo marcada pelo lançamento, em 1957, do texto Questão do Método, em seguida publicado em conjunto, em 1960, com Crítica da Razão Dialética. Entretanto, Munné não se interessa por pensar a continuidade entre ambas as etapas, o que, para o autor, teria um cunho filosófico pouco importante ao seu trabalho. Assim, termina por manter uma divisão, afirmando que há aspectos marcadamente distintos entre ambos os períodos.

Por outro lado, autores como Cannon (1991), Moutinho (1995), Schneider (2002), Bornheim (2007) e Da Silva (2010) concordam que o que há entre os dois períodos é uma relação de continuidade. Bornheim (2007, p. 228) afirma que "de O Ser e o Nada à Crítica da Razão Dialética há, pois, uma evolução considerável no pensamento de Sartre; mas há também uma profunda unidade nesta evolução". Da Silva (2010), por sua vez, pensa na existência de dois momentos, mas também de um esforço em Sartre para aproximá-los. Segundo o autor, "manter a subjetividade da primeira fase de sua obra e, ao mesmo tempo, aproximar-se do marxismo - esse é o objetivo do período de gestação da Crítica" (Da Silva, 2010, p. 18). Ainda segundo esse autor (Da Silva, 2010, p. 19), “(...) num movimento ascendente, o pensamento de Sartre parte da fenomenologia, vai à ontologia, flerta com a metafísica; em seguida retorna ao cotidiano pela via da dialética marxista”. Cannon (1991, p. 163), a seu turno, escreve que "embora a mudança [de uma etapa a outra], como alguns críticos evidenciam, não tenha significado um abandono de sua ontologia prévia, [a escrita de Questão do Método e Crítica da Razão Dialética] é definitivamente um enriquecimento em relação a suas posições iniciais (...)". A autora aponta, junto com Bornheim, para certa evolução do pensamento de Sartre. Discordo desta perspectiva evolutiva, que parece apontar para o desenvolvimento de uma potencialidade dentro do pensamento de Sartre, mas concordo com o olhar para a unidade entre os diferentes momentos de sua elaboração.

O próprio Sartre, nos anos 1970, em entrevista concedida à revista New Left e que consta no livro Situations, IX, afirma que "O problema fundamental [que atravessa a mudança de posição da chamada primeira etapa para a segunda] é o da minha relação com o marxismo. [...] isso pode ajudar a compreender porque eu mudei tão radicalmente de ponto de vista após a Segunda Guerra Mundial" (Sartre, 1972, p. 99). Ora, como pensar em continuidade quando o próprio Sartre fala em mudança radical? Entretanto, ele também reconhece que há continuidades e pontos de contato. É nesse sentido que, por exemplo, em outra entrevista 
(Sartre, 1976), para o jornal francês Le Monde, Sartre percebe como questões presentes em $O$ Imaginário participam da elaboração da biografia de Flaubert, obra inacabada começada em 1955.

Penso ser importante perceber que há uma trajetória intelectual em que certos aspectos vão se sedimentando, certos interesses se mantêm e se repetem ao longo de toda a produção do filósofo. Se ao pensar na Psicanálise Existencial é a pessoa e seu projeto que estão em evidência, em uma perspectiva mais singular, não há ali carência de mundo, de social, embora este não seja ressaltado. Tal ênfase será dada a partir, justamente, das reflexões do método progressivo-regressivo.

\section{O Método Progressivo-regressivo: um Fim sem Final}

As relações de Sartre com o marxismo são fundamentais para a obra Questão do Método (Sartre, 2002). Nela, o filósofo estabelece uma diferenciação entre filosofia e doutrina, sendo aquela, em linhas gerais, um grande corpus que consegue compreender o horizonte histórico em que foi produzido, enquanto a doutrina seria uma variação deste corpus. Deste modo, ele defende que o marxismo é a filosofia necessária daquele tempo - a obra é escrita em 1957 -, mas que carece de um método para realizar tal análise da história, com o que a doutrina existencialista poderia contribuir.

O problema da filosofia marxista como vinha sendo colocada em cena por diferentes pensadores, era o modo como ela operava uma universalização da história. Adotava-se um conceito externo ao processo histórico, forjado pelo intelectual que considerava o período, e se acreditava definir a totalidade da experiência humana a partir dali: a luta de classes, a burguesia, o capital, são apenas algumas das ideias que embasaram a construção de uma história totalizada. Para Sartre, "o esquema constitutivo dessa hipótese é universalizante; não é totalizante; determina uma relação, uma função e não uma totalidade concreta. O marxista abordava o processo histórico com esquemas universalizantes e totalizadores" (Sartre, 2002, p. 33).

O que se depreende desta indicação, portanto, é que o método que o existencialismo de Sartre pode emprestar ao marxismo nessa busca pela compreensão da história universalizada deve atuar no sentido de recolocar o particular na universalização. Como assevera Da Silva (2010, p. 248), o marxismo "tem muita pressa em totalizar" a história. Se é possível fazê-lo, para Sartre, é apenas no registro de uma totalidade singular, de um singular universal, que deve ser estabelecido justamente no movimento entre um e outro polo dessa copla: 
[...] existencialismo e marxismo visam o mesmo objeto, mas o segundo reabsorveu o homem na ideia, enquanto o primeiro o procura por toda parte onde ele está, em seu trabalho, em sua casa, na rua. Com toda certeza, não pretendemos [...] que esse homem real seja incognoscível. Dizemos apenas que ele não é conhecido. (Sartre, 2002 , pp. 35, grifos no original)

Da Silva (2010, p. 18) é bastante explícito quanto a essa proposta de junção de Sartre de sua doutrina existencial à filosofia marxista.

Se para levar esse projeto a termo será necessário fazer concessões e lapidações, que seja: a liberdade fará sua oferta no altar da síntese filosófica. Mas também o marxismo terá que ofertar algo: Sartre entende que essa doutrina distancia teoria e prática ao sujeitar o homem (indivíduo) à Ideia; o existencialismo é o único que pode verdadeiramente unir infra e superestruturas, porque apenas ele pode encontrar o homem onde quer que ele esteja. (Da Silva, 2010, pp. 18)

Concordo com o autor que é necessária uma dupla hibridização, do existencialismo de Sartre e do marxismo, neste labor por uma visada conjunta. Cabe ao marxismo acolher a parte analítico-regressiva da proposta, que Sartre buscará numa psicanálise ${ }^{4}$, e ao existencialismo, englobar o retorno ao social operado pelos marxistas. Se em $O$ Ser e o Nada Sartre poderia ser criticado por enfatizar o caráter singular, sua proposta aqui é evidenciar o movimento do singular no universal e do universal no singular, de um ao outro, sem cessar, como se numa dança. Trata-se de um movimento dialético.

Em Questão do Método e Crítica da Razão Dialética, Sartre elabora uma metodologia para as ciências sociais em geral que é mais dialética do que analítica - que atenta para análise apenas como um dos momentos de um método progressivo-regressivo. Esse método, que Sartre adapta do sociólogo marxista Henri Lefebvre, tem três momentos: (1) um momento de descrição fenomenológica [...]; (2) um momento analítico-regressivo - um retorno à história do indivíduo ou grupo a momentos anteriores; e (3) um momento sintético-progressivo que se move do passado ao presente numa busca por redescobrir o presente em toda sua complexidade. (Cannon, 1991, pp. 22) 
É importante frisar que, em sua obra, Cannon (1991) pensa nas relações específicas entre o existencialismo e as psicanálises, freudiana e lacaniana em especial. Assim, penso que é sob o peso dessas psicanálises que ela compreende o movimento progressivo-regressivo como um caminho temporal, do passado ao presente dos analisandos. Acredito que isso também seja verdade, mas que, naquilo que tem de relação mais direta com o marxismo, o método progressivo-regressivo em Sartre é um movimento dialético que sai regressivamente do social para o indivíduo e progressivamente do indivíduo para o social. Esse movimento dialético, reitero, também engloba o movimento temporal entre passado e presente, de modo a elucidar o projeto fundamental pelo qual cada humano se faz pessoa, se escolhe e se objetiva no mundo.

A busca apressada pela totalização não é um risco presente apenas nas análises marxistas que Sartre criticava. Tal risco é vivenciado constantemente na prática clínica. Os “ídolos explicativos" do contemporâneo adquirem outras complexidades: as patologias, os diagnósticos, os modelos cognitivos, enfim, há uma miríade de elementos que perfazem uma clínica que se apressa por totalizar a pessoa que se apresenta para o encontro com o terapeuta. Tais totalizações ignoram, na maior parte das vezes, o polo de sua necessária destotalização, promovendo um novo engessamento do analisando em uma versão de si que, embora talvez diferente do modo como ele chegou ao consultório, é ainda encapsulante. No campo das humanidades, toda totalidade só pode existir como totalidade destotalizada, ou seja, o esforço de totalização e destotalização não se finda.

A reflexão sobre os métodos em Sartre nos abre caminhos para olharmos para um fazer clínico que seja fluido. Esta fluidez não é vazia de totalizações, mas reconhece que toda compreensão possível de um analisando requer sempre um equivalente movimento de destotalização. Esse caminho aponta para a necessidade da consideração constante das determinações sociais, culturais, familiares, mundanas, que pesam sobre nossos analisandos e, ao mesmo tempo e por outro lado, de como cada um deles (cor)responde a tais chamamentos, em um jogo constante e infindo de constituir-se.

Tal jogo deve ser construído no movimento dialético entre absoluto/universal e singular/particular: ora de modo progressivo, em que partimos deste para aquele, ora regressivo, no movimento inverso. É apenas por meio desse movimento que se pode aclarar o sentido, qual seja, o projeto existencial de cada existente concreto, aquilo que move as rodas da história, uma vez que "o sentido projetado da ação aparece na realidade do mundo para tomar sua verdade no processo de totalização" (Sartre, 2002, p. 31). 
Aliás, a própria obra de Sartre evidencia esse fluxo. Não para por aqui, no método progressivo-regressivo. Seria de se imaginar que, por exemplo, no seu projeto de biografia de Flaubert, posterior a esta proposição, ele se valesse unicamente desta metodologia. Diz-nos ele, contudo, na já citada entrevista ao jornal Le Monde, por exemplo, sobre como estabelece o fio conector entre os diversos momentos de vida de seu biografado que

sou obrigado a imaginar: se pego, por exemplo, uma carta de 1838 e uma outra de 1852, estes são documentos que não foram jamais relacionados entre si pelo próprio Flaubert nem por seus correspondentes ou críticos. Naquele momento, essa relação não existia. Se eu a faço, é porque imagino. E uma vez que imaginei, isso pode me dar uma relação real. (Sartre, 1976, pp. 95)

Como não perceber aqui ecos da discussão de Sartre em $O$ Imaginário, ou ainda resquícios daquilo que definiu como sendo o método da psicanálise existencial, a comparação? Portanto, o próprio filósofo "dança" com suas obras pregressas. Continua, descontinua, move-se para lá e para cá como em uma valsa. Assim, segue sua produção. Penso que esses movimentos de Sartre abrem brechas para as reflexões para uma clínica fenomenológica-existencial. Se a todo instante estamos pensando em como os métodos podem possibilitar a compreensão de uma pessoa, singularização no universal, e ao mesmo tempo, como o mundo é também efeito dessas singularizações, é evidente que a clínica psicológica é contemplada por este pensamento.

Por fim, é importante reconhecer que a empreitada aqui realizada não traz respostas acalentadoras, de uma clínica pré-pronta, modular, feita de pré-recomendações e passo-apasso. Trata-se de um fazer inseguro, tateante, que, muitas das vezes, nos assalta com a percepção de que não há respostas prévias para o caminho percorrido com cada analisando. Estas incertezas e a dificuldade de lidar com elas, percebo diariamente diante do contato com os estagiários em formação e de minha própria prática clínica. Não é fácil nos mantermos reiteradamente no esforço diário para a construção de uma clínica que aposte no universalsingular, no progressivo-regressivo, na totalidade-destotalizada, mas, creio, este é o único fazer verdadeiramente possível. 


\section{Referências}

Bachelard, G. (1978) A filosofia do não: O novo espírito científico: A poética do espaço. São Paulo: Abril Cultural.

Bornheim, G. (2007). Sartre: Metafísica e existencialismo. São Paulo: Perspectiva.

Campos, C. M., \& Alt, F. (2009). Situações Sartreanas: A trajetória de vida de Lucien Fleurier como um esboço de Psicanálise Existencial. In A. M. L. C. Feijóo (Org.), Psicologia Clínica e Filosofia (pp. 187-220). Belo Horizonte: Fundação Guimarães Rosa.

Cannon, B. (1991). Sartre \& Psychoanalysis: An existentialist challenge to clinical metatheory. Lawrence, Kansas: University Press of Kansas.

Cohen-Solal, A. (2008). Sartre: Uma biografia. Porto Alegre: LP\&M.

Da Silva, L. D. (2010). A filosofia de Sartre: Entre a Liberdade e a História. São Carlos, SP: Claraluz.

Lasowski, A. W. (2011). Jean-Paul Sartre: Une introduction. Paris: Pocket.

Moutinho, L. D. S. (1995). Sartre: Existencialismo e liberdade. São Paulo: Moderna.

Moutinho, L. D. S., \& Prado Jr., B. (1996) Apresentação. In J.-P. Sartre, O Imaginário (pp. 57). São Paulo: Ática.

Munné, F. (1982). Psicologías Sociales Marginadas: La línea de Marx en la Psicología Social. Barcelona: Hispano Europa S.A.

Pontalis, J.-B. (2010). En marge des nuits. Paris: Gallimard.

Renaut, A. (1993). Sartre: Le dernier philosophe. Paris: Grasset \& Fasquelle.

Sartre, J.-P. (1972). Situations, IX. Paris: Gallimard.

Sartre, J.-P. (1976). Situations, X. Paris: Gallimard.

Sartre, J.-P. (1991). The transcendence of the ego: An existentialist theory of consciousness. Nova Iorque: Hill and Wang.

Sartre, J.-P. (1996). O Imaginário. São Paulo: Ática.

Sartre, J.-P. (2002). Questão do Método. In J.-P. Sartre, Crítica da Razão Dialética (pp. 19123). Rio de Janeiro: DP\&A.

Sartre, J.-P. (2007). O Ser e o Nada: Ensaio de Ontologia Fenomenológica. Petrópolis, RJ: Vozes.

Sartre, J.-P. (2008). A Imaginação. Porto Alegre: L\&PM.

Sartre, J.-P. (2011). Les mots. Paris: Gallimard.

Schneider, D. R. (2002). Novas Perspectivas para a Psicologia Clínica: Um estudo a partir da obra "Saint Genet: Comédien et martyr" de Jean-Paul Sartre (Tese de doutorado). 
Pontifícia Universidade Católica de São Paulo, São Paulo, SP, Brasil. Recuperado de http://www.psiclin.ufsc.br/files/2010/05/Tese.pdf

Schneider, D. R. (2008). O método biográfico em Sartre: Contribuições do Existencialismo para a Psicologia. Revista Estudos e Pesquisas em Psicologia, 8(2). Recuperado de https://www.e-publicacoes.uerj.br/index.php/revispsi/article/view/10745/8437

\section{Endereço para correspondência}

\section{Rodolfo Rodrigues de Souza}

Rua Barão de Mesquita, 605 apto 303, Tijuca, Rio de Janeiro - RJ, Brasil. CEP 20540-001

Endereço eletrônico: rodolforsouza@gmail.com

Recebido em: 05/07/2020

Aceito em: 04/09/2020

\section{Notas}

* Doutorando em Psicologia Social pelo PPGPS/UERJ. Mestre em Psicologia Social pelo mesmo programa. Especialista em Psicologia Clínica na Abordagem Fenomenológico-Existencial. Professor no Centro Universitário Celso Lisboa.

${ }^{1}$ Todas as citações de referências estrangeiras são produto de livre tradução. Por questões de extensão, opto por não transcrever o original.

${ }^{2}$ Referência não literal ao título de Marquês de Sade (2008), lançado em 1795, "La Philoshophie dans le Boudoir", obra de domínio público conhecida em português como A Filosofia na Alcova.

${ }^{3}$ Entretanto, a autora, neste momento de seu livro, está diretamente comentando o texto sartriano Questão do Método, publicado como primeira parte de Crítica da Razão Dialética (Sartre, 2002). Assim, pode-se dizer que ela subverte a ideia presente neste texto, uma vez que ele não comenta a psicanálise existencial. Sartre está preocupado em estabelecer ali exatamente o método progressivo-regressivo e em todos os momentos em que se refere à psicanálise, o faz em relação à teoria e ao método freudianos. O próprio trecho que a autora cita, encontrado na edição brasileira de Crítica da Razão Dialética (Sartre, 2002, p. 57), é em referência direta à Freud e não à parte que agora comento acerca de O Ser e o Nada. Contudo, acredito que essa constatação não invalidade a ideia de que a psicanálise existencial, para Cannon, é também um método.

${ }^{4}$ É curioso notar que em Questão do Método Sartre não retoma diretamente sua proposta de psicanálise existencial, mas aponta para a compreensão de que a visada que carece o marxismo pode ser encontrada na psicanálise freudiana. Embora o filósofo não repita isso aqui, acredito que seja uma psicanálise freudiana adaptada, discussão que ele já realizara em O Ser e o Nada.

Este artigo de revista Estudos e Pesquisas em Psicologia é licenciado sob uma Licença Creative Commons Atribuição-Não Comercial 3.0 Não Adaptada. 